\title{
Pulmonary blood volume indexed to lung volume is reduced in newly diagnosed systemic sclerosis compared to normals - a prospective clinical cardiovascular magnetic resonance study addressing pulmonary vascular changes
}

Mikael Kanski ${ }^{1}$, Håkan Arheden ${ }^{1}$, Dirk M Wuttge ${ }^{2}$, Gracijela Bozovic ${ }^{3}$, Roger Hesselstrand ${ }^{2}$ and Martin Ugander $^{1 *}$

\begin{abstract}
Background: Pulmonary involvement, manifested as pulmonary arterial hypertension or pulmonary fibrosis, is the most common cause of death in systemic sclerosis (SSc). We aimed to explore the feasibility of detecting early pulmonary involvement in SSC using recently developed non-invasive quantitative measures of pulmonary physiology using cardiovascular magnetic resonance (CMR).

Methods: Twenty-seven SSC patients ( 9 men, $57 \pm 13$ years) and 10 healthy controls ( 3 men, $54 \pm 9$ years) underwent CMR to determine the pulmonary blood volume (PBV) and the PBV variation (PBV) throughout the cardiac cycle. Patients underwent Doppler echocardiography, high-resolution computed tomography (HRCT), and pulmonary function testing by spirometry. Comparisons were performed using the unpaired t-test and linear regression analysis was performed with Pearson's correlation coefficient ( $r$ ).

Results: Compared to healthy controls, the PBV indexed to lung volume (PBVI) was lower in patients (16 \pm 4 vs $20 \pm$ $5 \%, p<0.05)$. There was no difference in PBV $(466 \pm 87$ vs $471 \pm 122 \mathrm{~mL}, p=0.91)$ or PBW/stroke volume (45 \pm 10 vs $40 \pm 6 \%, p=0.09$ ). There were no significant correlations between PBVI and pulmonary artery pressure estimated by Doppler $(p=0.08)$ the lung's diffusion capacity for carbon monoxide $\left(D L_{c o}\right)(p=0.09)$, vital capacity $(p=0.45)$, or pulmonary fibrosis by HRCT $(p=0.74)$.

Conclusions: This study is the first to measure the PBV in humans using CMR. Compared to healthy controls, newly diagnosed SSC patients have a reduced amount of blood in the pulmonary vasculature (PBVI) but unchanged pulmonary vascular distensibility (PBW/stroke volume). PBVI is unrelated to $\mathrm{DL}_{\mathrm{CO}}$, pulmonary artery pressure, vital capacity, and the presence of pulmonary fibrosis. PBVI may be a novel parameter reflecting vascular lung involvement in early-stage SSc, and these findings may be consistent with pathophysiological changes of the pulmonary vasculature.
\end{abstract}

\footnotetext{
* Correspondence: martin@ugander.com

'Department of Clinical Physiology, Lund University and Lund University

Hospital, Lund, SE-221 85 Lund, Sweden

Full list of author information is available at the end of the article
} 


\section{Background}

The diagnosis of systemic sclerosis (SSc) entails a 10-15\% lifetime risk of developing pulmonary arterial hypertension (PAH) [1-3]. PAH develops as a result of pulmonary vascular pathology whereas pulmonary hypertension may be secondary to severe interstitial lung disease [4]. $\mathrm{PAH}$ is diagnosed by right heart catheterization and pulmonary fibrosis is identified by high-resolution computed tomography (HRCT) of the chest. Increased pulmonary vascular pressures and progressive pulmonary fibrosis, if left untreated, often lead to right heart failure and eventually death. Therefore, early detection of pathological changes in the lungs is important in order to stall the progress of disease by medical therapy. The benefit of early detection of PAH has been exemplified by the improvement in haemodynamics and survival in a screening cohort compared to a detection cohort of SSc patients [5]. Since the introduction of medical treatment with angiotensin-converting enzyme inhibitors in SSc with renal involvement, pulmonary involvement is now the leading cause of death in SSc [6]. Furthermore, pulmonary fibrosis, which may occur in the absence of skin lesions, [7] may lead to an impaired gas exchange due to altered physiology in the alveolae. This impairment can be measured by studying the diffusion capacity for carbon monoxide in the lungs $\left(\mathrm{DL}_{\mathrm{CO}}\right)[8]$.

Cardiovascular magnetic resonance (CMR) has proven to be a highly accurate and precise tool for flow quantification and detection of small changes in blood flow [9]. Recent developments in CMR include the ability to quantify the pulmonary blood volume (PBV), as well as the variation in PBV throughout the cardiac cycle, also called the PBV variation (PBVV) normalized to the stroke volume in the pulmonary trunk (PBVV/SV). During systole, the pulmonary blood volume will increase due to the Windkessel effect. The stiffer the blood vessels, the lower the pulmonary blood volume variation. Measuring the distensibility in the pulmonary trunk alone will render information about the distensibility status of the proximal vessels, whereas the rest of the pulmonary vasculature will not be accounted for. By comparison, $\mathrm{PBVV} / \mathrm{SV}$ is a measure of the global pulmonary vascular distensibility, and it is not related to change in pulmonary artery cross-sectional area $[10,11]$. However, little is known about how these measures are affected by pulmonary involvement such as that which occurs in SSc. It has been suggested that SSc can lead to a hyper-reactivity in the pulmonary vessels similar to the Raynaud's phenomenon seen in the peripheral circulation [12]. However, a study assessing pulmonary haemodynamics during right heart catheterization and infusion of cold liquids showed no presence of cold induced vasoconstriction in SSc, and concluded that the constriction is rather caused by proliferation within the pulmonary arterioles [13]. This constriction in the pulmonary vessels could theoretically yield a smaller PBV in both absolute measures and indexed to lung volume (PBVI). Notably, data are not available to support this hypothesis. Furthermore, the PBV has previously not been studied in healthy subjects using CMR. Since an early detection of pulmonary involvement may have implication for patient care, the aim of this study was to explore the clinical usefulness of novel CMR techniques studying the pulmonary blood pool, including the PBV, and the PBV variation (PBVV) throughout the cardiac cycle using CMR, in SSc and healthy controls.

We hypothesized that, compared to healthy individuals, patients with SSc would have a decreased PBVI due to arteriolar involvement, and a lower PBVV/SV as a result of decreased pulmonary vascular distensibility. Therefore, the aim of this study was to prospectively explore the PBV, PBVI, and PBVV in healthy controls and patients with newly diagnosed SSc using CMR.

\section{Methods \\ Study design}

Twenty-seven consecutive newly diagnosed SSc patients, presenting to the Department of Rheumatology, Lund University Hospital, Lund and 10 healthy volunteers underwent CMR using a 1.5-T scanner (Intera, Philips, Best, the Netherlands) and a five-element cardiac coil. Out of 27 patients, 18 (67\%) were diagnosed with limited cutaneous SSc, and three (11\%) with diffuse cutaneous SSc. Six patients (22\%) fulfilled the criteria for early SSc suggested by LeRoy [14]. Disease duration was calculated from first non-Raynaud's manifestation. The healthy volunteers were recruited by local advertisement. All volunteers had a normal electrocardiogram and did not have any previous cardiac history or cardiopulmonary medication. The study was approved by the Lund University Human Subjects Research Ethics Committee, and all subjects provided written informed consent. All image analysis was performed using the Segment software which is freely available for research use (Segment v1.8, Medviso, Lund, Sweden, http://segment.heiberg.se) [15].

\section{Pulmonary transit time}

The pulmonary transit time (PTT) was defined as the time for a $2 \mathrm{ml}$ intravenously administered contrast bolus (gadoterate meglumine, $279.3 \mathrm{mg} / \mathrm{ml}$, Gd-DOTA, Dotarem, Gothia Medical, Billdal, Sweden) to pass from the pulmonary trunk to the left atrium (Figures 1 and 2). The contrast, followed by $20 \mathrm{ml}$ of saline, was injected at $4 \mathrm{ml} / \mathrm{s}$ using a power injector. Images were acquired in an atrial short-axis plane bisecting the left atrium and the pulmonary trunk using a saturation recovery steady-state free precession imaging sequence. Typical CMR parameters were: slice thickness $20 \mathrm{~mm}$, pixel size $1.3 \times 1.3 \mathrm{~mm}$, 


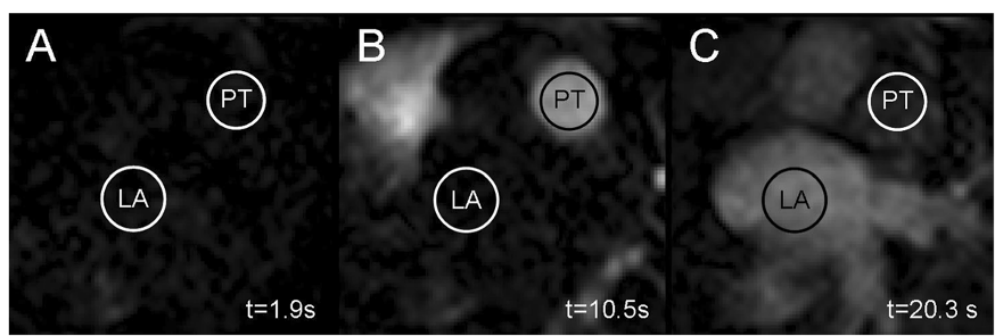

Figure 1 Pulmonary transit time (PTT). Time-resolved atrial short-axis SSFP CMR images (TR/TE 2.5/1.2 ms; flip angle 50) bisecting the pulmonary trunk (PT) and the left atrium (LA) acquired during the first pass of an intravenous bolus of CMR contrast agent (Gd-DOTA). Panels A-C show the passage for $2 \mathrm{~mL}$ contrast bolus through the PT to the LA. Contrast intensity was measured in a region of interest in the PT and the LA, respectively. Time (t) is shown in seconds $(\mathrm{s})$ in the lower corner on right hand side of the respective panel. A: time of contrast bolus injection, $\mathbf{B}$ : contrast bolus passing through PT, and $\mathbf{C}$ : arrival in LA. Note the change in signal intensity over time in the respective regions of interest.

temporal resolution $130 \mathrm{~ms}$, TR/TE: $2.5 / 1.2 \mathrm{~ms}$, flip angle $50^{\circ}$. The PTT was defined as the time between the time points of the weighted mean for each time-intensity curve, respectively, as previously validated [11].

\section{Pulmonary blood volume}

The pulmonary blood volume (PBV) was measured as the product of the PTT and cardiac output, as previously described and validated [11]. Cardiac output was assessed by CMR flow measurement of a cross section of the pulmonary trunk or aorta using a non-segmented phase contrast velocity-encoded gradient echo sequence with retrospective ECG triggering and established analysis methods [10]. Typical CMR parameters were: slice thickness $6 \mathrm{~mm}$, frames per cardiac cycle: 35, TR/TE: $8.7 / 5.3 \mathrm{~ms}$, flip angle $15^{\circ}$, pixel size $1.2 \times 1.2 \mathrm{~mm}$, velocity encoding gradient $200 \mathrm{~cm} / \mathrm{s}$.

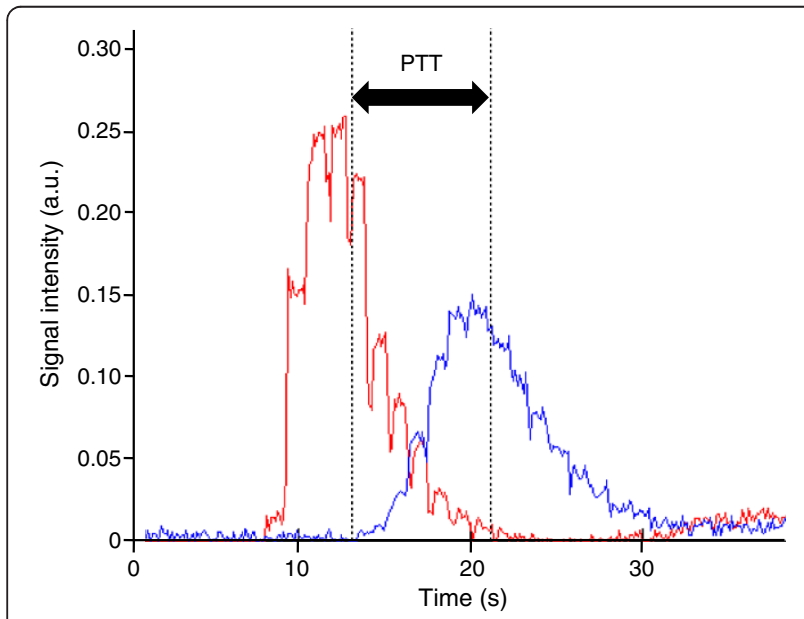

Figure 2 Measurement of the pulmonary transit time (PTT). The plot shows signal intensity (in arbitrary units, a.u.) over time for regions of interest in the pulmonary trunk (red) and the left atrium (blue), respectively. The black dotted vertical lines indicate the center of gravity for the respective curve. The double-headed arrow indicates the PTT.

\section{Pulmonary blood volume variation}

Flow measurement of the pulmonary trunk and all the pulmonary veins, respectively, were acquired as previously described (Figure 3, panel A and B) [10]. The difference in arterial and venous blood flow over time (Figure 3, panel C) was integrated, yielding the cumulative blood volume in the pulmonary circulation (Figure 3, panel D). The PBV variation (PBVV) was defined as the difference between the maximum and the minimum of the cumulative volume variation over the cardiac cycle. Arterial and venous pulmonary blood flow was obtained using the same sequence as for cardiac output.

\section{Pulmonary blood volume indexed to lung volume}

The pulmonary blood volume indexed to lung volume (PBVI) was defined as PBV/pulmonary volume. The pulmonary volume was measured by manual planimetry in a transverse SSFP CMR image stack covering the lungs during end-expiratory breathhold (Figure 4). Typical imaging parameters were: number of slices $50-60$, slice thickness $5 \mathrm{~mm}$, TR/TE: $3.2 / 1.6 \mathrm{~ms}$, flip angle $80^{\circ}$, pixel spacing $1.4 \times 1.4 \mathrm{~mm}$, temporal resolution (duration of acquisition per image): $400 \mathrm{~ms}$.

\section{Left and right ventricular functional parameters}

Left and right ventricular end diastolic volume, end systolic volume, stroke volume, and ejection fraction were measured by CMR and manual planimetry using established techniques [16]. In patients, right ventricular endocardical delineation was performed in the axial plane, in the healthy controls right ventricular delineation was performed in the short-axis plane. Images were acquired using a cine SSFP sequence. Typical CMR parameters included: TR/TE: 2.9/1.5 ms, flip angle: $60^{\circ}$, frames per cardiac cycle: 30 , reconstructed pixel size: $1.4 \times 1.4 \mathrm{~mm}$ with an acquisition resolution of $2.1 \times 2.3 \mathrm{~mm}$, slice thickness: $8 \mathrm{~mm}$, no slice gap, temporal resolution: $40 \mathrm{~ms}$. Body surface area was calculated using the Mosteller formula [17]. 


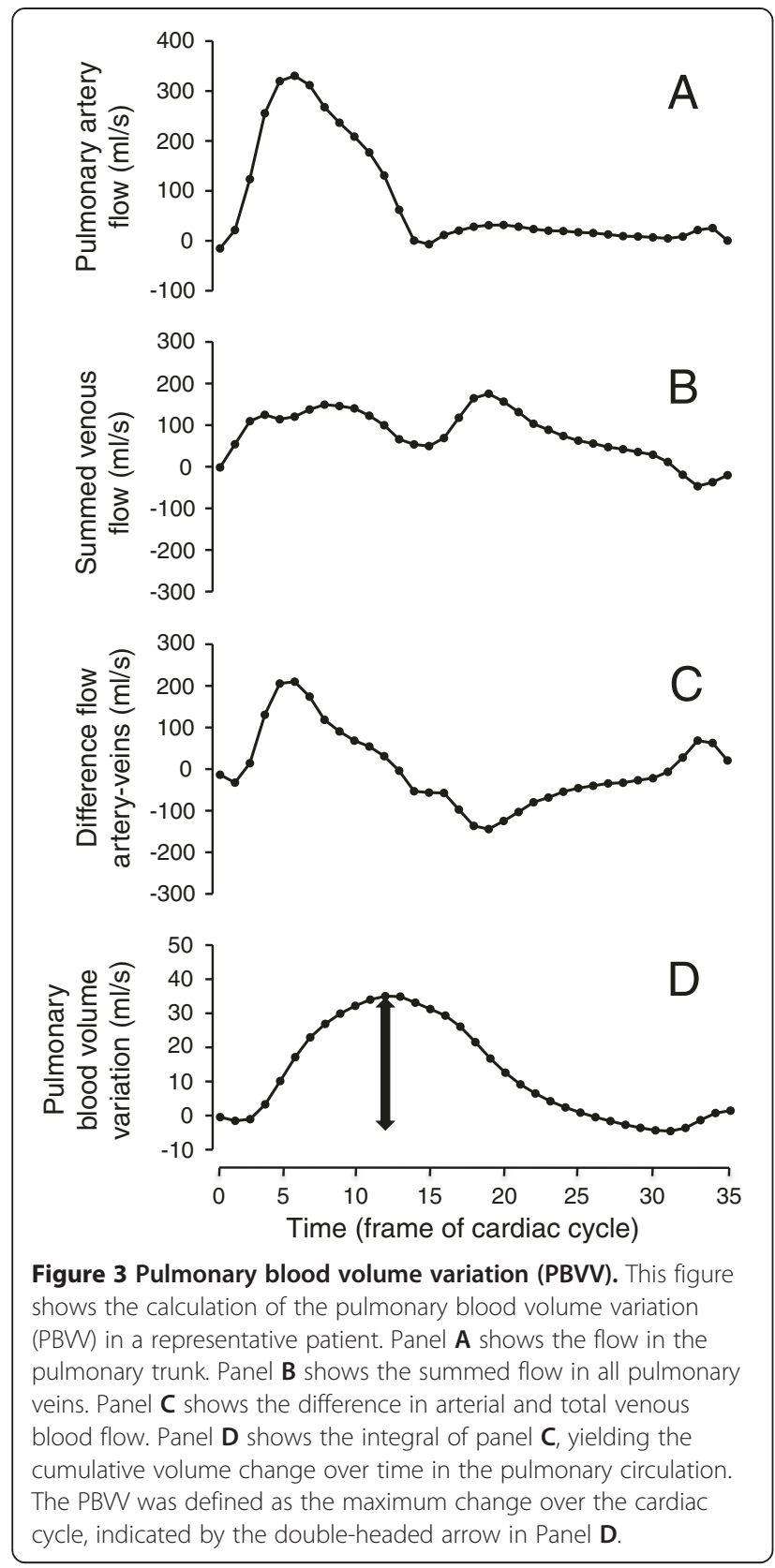

\section{HRCT, echocardiography, and lung function}

HRCT was performed using a Philips Brilliance 16-slice or 40-slice CT system (Philips, Best, The Netherlands). Data was visually assessed with regards to the presence of fibrosis-related pathology. Fibrosis was defined by the presence of traction bronchiectasis within areas of ground-glass opacity, and reticulations [18]. Patients were compared with regards to presence or absence of ground-glass opacity and/or reticulations and/or traction bronchiectasis by HRCT.

Echocardiography included Doppler measurement of the maximum velocity gradient across the tricuspid valve, and assessment of inferior vena cava size and variation in

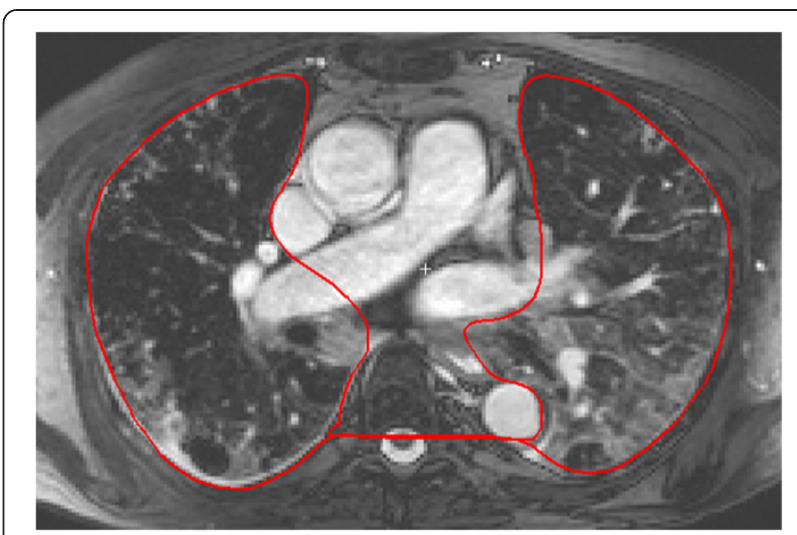

Figure 4 Assessment of the pulmonary volume. Transversal SSFP CMR was undertaken covering the entire lung field with the patient in functional end-expiratory state. The pulmonary volume was measured by planimetry in each slice, typically 50-60 slices. The figure illustrates a single representative transverse slice through the thorax. The red region of interest illustrates the region included in the pulmonary volume in this slice. The delineated area includes the functional residual capacity, the pulmonary parenchyma, and the pulmonary vessels within the lung parenchyma, but excluding the greater proximal pulmonary vessels and the aorta.

diameter during respiration. Central venous pressure was estimated in increments of 5,10 , or $15 \mathrm{mmHg}$ by an experienced observer based on caval physiology. Systolic pulmonary artery pressure was calculated using the tricuspid velocity gradient and caval physiology [19] using a Philips Sonos 7500 system (Soma Technology Inc, Bloomfield, CT, USA). The upper limit by echocardiography for PAH was $30 \mathrm{mmHg}$. Patients with suspected PAH also underwent invasive measurement. An invasive mean pulmonary arterial pressure of $\geq 25 \mathrm{mmHg}$, pulmonary vascular resistance $\geq 3.0$ Woods units, and capillary wedge pressure $<15 \mathrm{mmHg}$ was defined as PAH.

Pulmonary function testing included assessment of the vital capacity (VC) and the diffusion capacity for carbon monoxide $\left(\mathrm{DL}_{\mathrm{CO}}\right)$ by the single-breath test.

\section{Statistics}

Comparisons were performed using GraphPad 6.0 for Windows (GraphPad Software, Inc, La Jolla, CA, USA). Following visual inspection of the data, comparisons between groups was tested using the parametric unpaired t-test. Differences between groups were also tested using non-parametric tests and this yielded results with identical levels of significance in all comparisons. Linear regression analysis was performed with Pearson's correlation coefficient (r). $\mathrm{p}<0.05$ was deemed statistically significant. Data are presented as mean \pm SD.

\section{Results}

Subject characteristics are described in Table 1. 
Table 1 Subject characteristics

\begin{tabular}{|c|c|c|}
\hline Characteristics & SSc & Controls \\
\hline Total (n) & 27 & 10 \\
\hline Male:female ratio & $3: 6$ & $3: 7$ \\
\hline Age (y) & $57 \pm 13$ & $54 \pm 9$ \\
\hline Body surface area $\left(\mathrm{BSA}, \mathrm{m}^{2}\right)$ & $1.81 \pm 0.16$ & $1.78 \pm 0.21$ \\
\hline Heart rate (bpm) & $76 \pm 11$ & $64 \pm 7+$ \\
\hline Cardiac index $\left(\mathrm{L} / \mathrm{min} / \mathrm{m}^{2}\right)$ & $3.3 \pm 0.8$ & $3.5 \pm 0.6$ \\
\hline LV stroke volume index $\left(\mathrm{mL} / \mathrm{m}^{2}\right)$ & $44 \pm 11$ & $54 \pm 7$ \\
\hline LV end diastolic volume index $\left(\mathrm{mL} / \mathrm{m}^{2}\right)$ & $72 \pm 16$ & $89 \pm 10$ \\
\hline LV end systolic volume index $\left(\mathrm{mL} / \mathrm{m}^{2}\right)$ & $29 \pm 9$ & $35 \pm 4$ \\
\hline LV ejection fraction (\%) & $61 \pm 8$ & $60 \pm 3$ \\
\hline RV stroke volume index $\left(\mathrm{mL} / \mathrm{m}^{2}\right)$ & $42 \pm 8$ & $53 \pm 7 \neq$ \\
\hline RV end diastolic volume index $\left(\mathrm{mL} / \mathrm{m}^{2}\right)$ & $79 \pm 23$ & $83 \pm 11$ \\
\hline RV end systolic volume index $\left(\mathrm{mL} / \mathrm{m}^{2}\right)$ & $37 \pm 22$ & $30 \pm 7$ \\
\hline RV ejection fraction (\%) & $55 \pm 13$ & $64 \pm 6$ \\
\hline Duration of disease $(\mathrm{y})$ & $6 \pm 8$ & \\
\hline Limited cutaneous SSc (n (\%)) & $18(67)$ & \\
\hline Diffuse cutaneous SSc (n (\%)) & $3(11)$ & \\
\hline Early SSc (n (\%)) & $6(22)$ & \\
\hline PAH (n (\%)) & $1(4)$ & \\
\hline
\end{tabular}

LV denotes left ventricle, RV denotes right ventricle. Bpm denotes beats per minute. Disease duration was calculated from first non-Raynaud's manifestation. Early SSc denotes patients fulfilling the LeRoy criteria. PAH denotes pulmonary arterial hypertension verified by right heart catheterization (defined as mPAP $>25 \mathrm{mmHg}$ ). Data are presented as mean $\pm \mathrm{SD}$. $\dagger$ denotes $p<0.01$, and $\neq$ denotes $p<0.001$ compared to patients with systemic sclerosis (SSc).

The pulmonary blood volume, pulmonary blood volume index, and pulmonary blood volume variation by CMR

The pulmonary blood volume indexed to lung volume (PBVI) in 27 patients compared to 10 healthy controls was $16 \pm 4$ vs $20 \pm 5 \%, \mathrm{p}<0.05$ (Figure 5). There were no difference in PBV $(466 \pm 87$ vs $471 \pm 122 \mathrm{~mL}, \mathrm{p}=0.91)$ or PBVV (32 \pm 8 vs $33 \pm 7 \mathrm{~mL}, \mathrm{p}=0.69$, Figure 6$)$. The LV stroke volume indexed to BSA in 27 SSc patients was lower compared to 10 healthy individuals $(44 \pm 11$ vs $54 \pm 7 \mathrm{~mL} / \mathrm{m}^{2}, \mathrm{p}<0.05$, respectively) (Figure 6). There was no difference in $\mathrm{PBVV} /$ stroke volume in patients compared to controls $(45 \pm 10$ vs $40 \pm 6, \mathrm{p}=0.09$, (Figure 5)). There was no correlation between PBVI and LV or RV function parameters. There were no correlation between PBVI and PBVV (patients: $\mathrm{r}=0.05, \mathrm{p}=0.81$; controls $\mathrm{r}=-0.02 \mathrm{p}=0.96$; for all: $\mathrm{r}=0.05, \mathrm{p}=0.77$ ).

\section{Echocardigraphy}

Twenty-three patients (85\%) had a suitable trace. There was no correlation between the estimated systolic pulmonary artery pressure assessed by Doppler echocardiography, and the PBVI $(\mathrm{p}=0.08, \mathrm{n}=23)$. The estimated

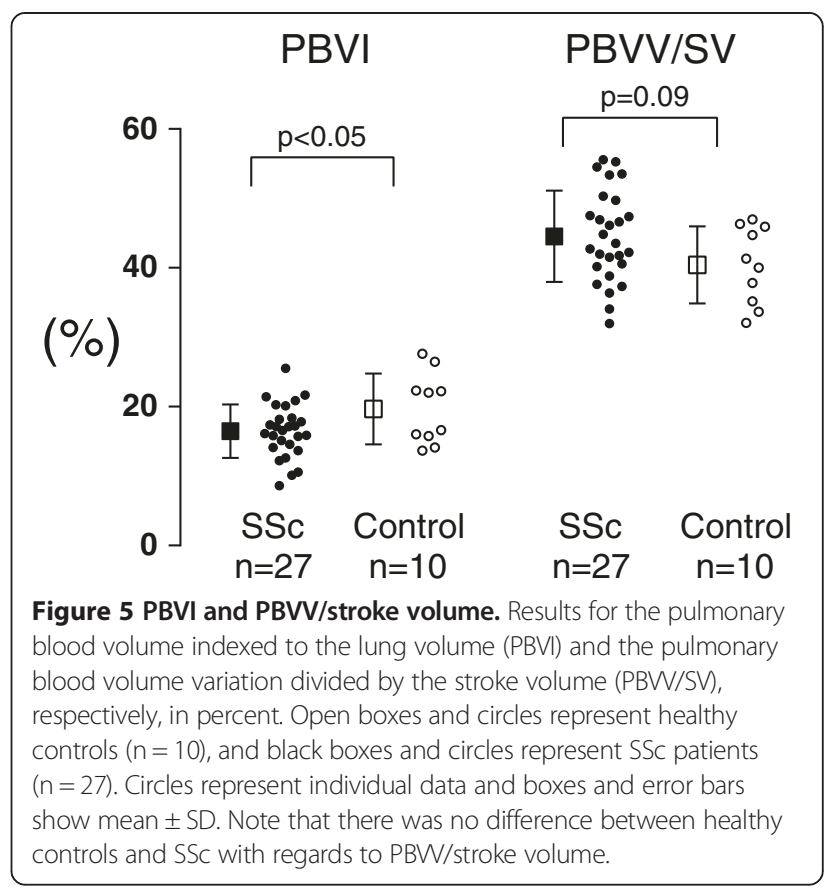

systolic pulmonary arterial pressure ranged between 26-94 mmHg.

\section{HRCT}

Fifteen out of 24 patients (63\%) were classified as having pulmonary fibrosis-related pathology by HRCT. Patients with pulmonary fibrosis by HRCT did not differ from those without pulmonary pathology with regards to PBVI ( $17 \pm 3$ vs $17 \pm 5 \%, \mathrm{p}=0.74$ ) or $\mathrm{PBVV} /$ stroke volume $(45 \pm 7$ vs $44 \pm 7 \%, \mathrm{p}=0.86)$.

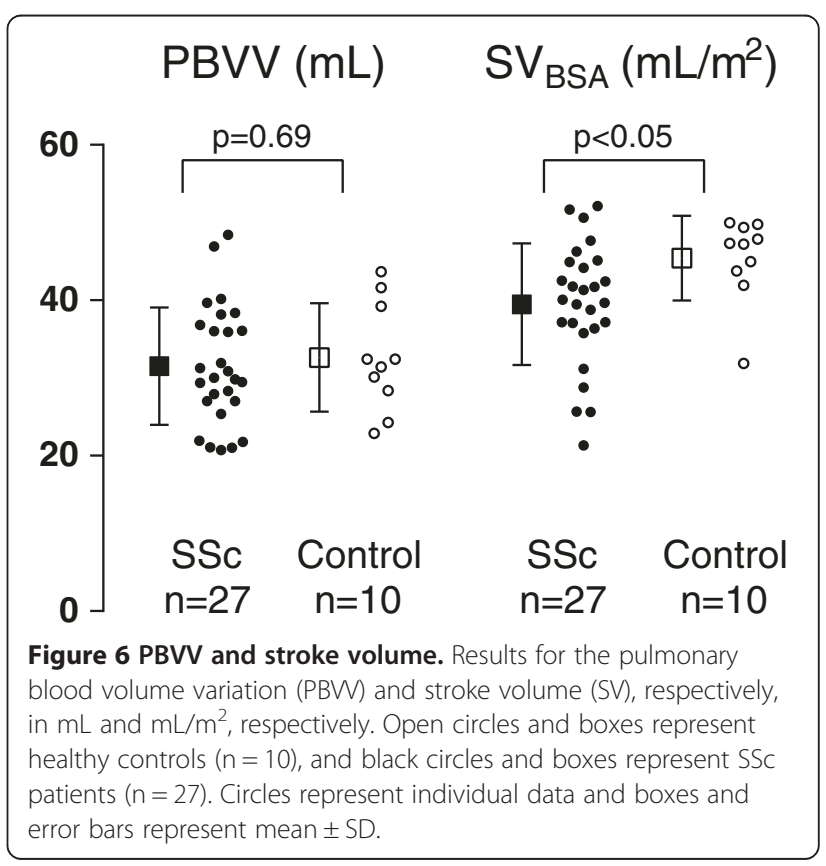




\section{Pulmonary function test}

The $\mathrm{DL}_{\mathrm{CO}}$ was assessed in 23 out of 27 patients (85\%) and the $\mathrm{VC}$ was assessed in 25 out of 27 patients (93\%). There were no correlation between the PBVI and $\mathrm{DL}_{\mathrm{CO}}$ or $\mathrm{VC}(\mathrm{p}=0.09$ and $\mathrm{p}=0.45$, respectively).

\section{Interobserver variability}

Two observers independently evaluated 10 randomly selected patient data sets. The interobserver variability for pulmonary volume, PBV, PBVI, and PBVV was $1 \pm 1 \%$, $4 \pm 12 \%, 2 \pm 12 \%$ and $1 \pm 6 \%$, respectively.

\section{Discussion}

The major finding in this study is that patients with newly diagnosed SSc, as a group, have a reduced amount of blood in the pulmonary vasculature normalized to lung size (PBVI) but an unaffected pulmonary vascular distensibility (PBVV/stroke volume), compared to healthy controls. There was no difference in absolute PBV between the groups. Furthermore, there was no relationship between PBVI and systolic pulmonary arterial pressure estimated by Doppler echocardiography. It remains unclear what the mechanisms are, however, our findings are compatible with previously suggested pathophysiological changes in the pulmonary vasculature [12]. Dopplerestimated pulmonary artery pressure, $\mathrm{DL}_{\mathrm{CO}}$, and presence of pulmonary fibrosis-related pathology measured either on HRCT or as reduced VC did not influence PBVI. Early pathophysiological changes in the pulmonary circulation may be the reason why patients with newly diagnosed SSc differ in PBVI compared to healthy individuals. Such changes may be important to recognize as a tool to select patients eligible for right heart catheterization since an early diagnosis of $\mathrm{PAH}$ is paramount to improve survival in SSc.

\section{PBV}

The current study is, to our knowledge, the first to measure the PBV by CMR in healthy controls and patients. The PBV has previously been assessed only in valvular heart disease using dye-dilution based techniques during invasive cardiac catheterization, radioactive isotope injection or echocardiography [20-24]. However, catheterization is associated with complications including perforation of great vessels, and echocardiography is both user-dependent and has limited precision when assessing cardiac output [25].

\section{PBVV and stroke volume}

There was a lower absolute stroke volume in SSc patients compared to healthy controls. This difference may be related to myocardial disease in the SSc patients. However, there was no difference in pulmonary vascular distensibility (PBVV/stroke volume) when comparing the groups. Previously, the PBVV/stroke volume has been shown to decrease in pigs that developed increased pulmonary arterial pressure following experimental acute myocardial infarction [11]. It appears that the changes in pulmonary arterial pressure in our cohort of SSc patients either were not of a magnitude sufficient to influence PBVV, or may have been the result of a different pathophysiological process compared to experimental acute myocardial infarction. PBVV has previously been measured using nitrous oxide body plethysmography or catheter-based thermodilution techniques [26,27]. The currently presented technique using CMR has the advantage that it is non-invasive, and, in contrast to plethysmography, measures the PBVV in both the arterial and the venous vessels.

\section{HRCT and $\mathrm{DL}_{\mathrm{CO}}$}

Pulmonary fibrosis-related pathology seen on HRCT may lead to non-perfused pulmonary volumes [18]. This, per se, could lead to a decrease in the PBVI. However, there was no difference in PBVI when comparing the presence or absence of HRCT-verified fibrosis-related pathology. This suggests that PBVI measures a pathophysiological mechanism independent of pulmonary fibrosis. In the very first descriptions of SSc patients developing $\mathrm{PAH}$, a declining $\mathrm{DL}_{\mathrm{CO}}$ but normal $\mathrm{VC}$ was a key feature. However, there was no correlation between the PBVI and $\mathrm{DL}_{\mathrm{CO}}$, which suggests that the PBVI may reflect pulmonary involvement prior to changes severe enough to alter $\mathrm{DL}_{\mathrm{CO}}$.

\section{Interpreting the PBVI}

The SSc patients in the present study displayed a wide range of PBVI values. This may be because the patients are in different stages of disease. However, some patients even had a higher value than the controls. This may be related to left ventricular dysfunction, leading to backward failure and an increased amount of blood in the pulmonary circulation. There was no correlation between estimated pulmonary artery pressure and PBVI. Previously, catheter-based techniques have been used to show an increased PBV in patients with stenosis or regurgitation in the mitral valve, $[22,28]$ presumably due to backward failure and distension of the pulmonary venous and/or pulmonary arterial blood pool. Consequently, the following pathophysiological mechanisms may apply to patients with SSc. On the one hand, pulmonary arteriolar proliferation may reduce the PBV, presumably on the arterial side, while on other hand, backward failure, if present, may increase the PBV, presumably on the venous side. Thus, SSc patients with a decreased arterial blood pool and simultaneous backward failure could hypothetically present with a PBVI within normal values or higher. 


\section{Limitations}

One limitation of the study may be the accuracy of measuring PBVV, since the PBVV is derived from up to 6 different flow measurements comprised of one measurement each from the pulmonary artery and at most 5 pulmonary veins, respectively. However, the interobserver variability between two experienced observers was low, and a previous study with identical methodology has shown good correspondence between the volumes of measured in- and outflow from the pulmonary circulation [10] and excellent agreement between flow-derived and planimetrically derived volume changes in the heart [9]. Furthermore, the comparison between the PBVI and PBVV and pulmonary arterial pressures were made using Doppler-echocardiography derived pressures. Invasive pressures were only acquired in three patients with suspected $\mathrm{PAH}$, and this is a limitation. Another limitation is that there currently is no gold standard to measure the pulmonary volume including the functional end-expiratory lung volume. Thus, a future comparison between CMR and computed tomography may be of value to address this issue. Moreover, test-retest variability would be of value to perform and this has not been done.

\section{Conclusions}

Compared to healthy controls, patients with newly diagnosed SSc have, as a group, a reduced amount of blood in the pulmonary vasculature (PBVI) but an unaffected pulmonary vascular distensibility (PBVV/stroke volume), not related to the presence of pulmonary fibrosis-related pathology on HRCT, estimated pulmonary artery pressure, $\mathrm{DL}_{\mathrm{CO}}$ or reduced VC. This implies that the PBVI may reflect the morphology of the SSc lung since the majority of the patients did not show any clinical sign of pulmonary involvement. These findings are consistent with an involvement of pulmonary arterioles in SSc. Therefore, in the case of reduced PBVI, an earlier medical treatment may be indicated in order to stall the progress of further pulmonary involvement. Also, this study shows the feasibility of assessing the PBV in healthy individuals and clinical SSc patients by using CMR. Further studies are justified to assess the clinical utility of PBVI as a noninvasive diagnostic and prognostic measure of pathophysiological changes in the pulmonary circulation.

\section{Competing interests}

The authors declare that they have no competing interests.

\section{Authors' contributions}

MK participated in data acquisition, performed the image analysis and data analysis, and drafted the manuscript. DMW participated patient recruitment. $\mathrm{GB}$ performed computed tomography image analysis. $\mathrm{RH}$ performed data acquisition, and coordinated patient recruitment. MU conceived the study, participated in data analysis, drafting the manuscript, and had full access to and was responsible for the integrity of the data. All authors participated in the design of the study, critically revised the manuscript for important intellectual content, and approved the final manuscript.

\section{Acknowledgements}

The authors thanks technicians Ann-Helen Arvidsson and Christel Carlander for assistance in data collection. This study was supported in part by the Swedish Research Council; the Swedish Heart-Lung Foundation; Lund University Faculty of Medicine; Lund University Hospital, Lund, Sweden; Region Skåne; the Apotekare Hedbergs fund; the Crafoord foundation; the Greta and Johan Kock foundation; the Alfred Österlund foundation; the 80Year Fund of King Gustav V; the Donation fund at the Department of Rheumatology; the Evy and Gunnar Sandberg Foundation; the Swedish Rheumatism Association and the Swedish Society of Medicine.

\section{Author details}

'Department of Clinical Physiology, Lund University and Lund University Hospital, Lund, SE-221 85 Lund, Sweden. 'Department of Rheumatology, Lund University and Lund University Hospital, Lund, SE-221 85 Lund, Sweden. ${ }^{3}$ Department of Radiology, Lund University and Lund University Hospital, Lund, SE-221 85 Lund, Sweden.

Received: 15 June 2011 Accepted: 11 September 2013

Published: 25 September 2013

\section{References}

1. Hachulla E, Gressin V, Guillevin L, Carpentier P, Diot E, Sibilia J, Kahan A, Cabane J, Francès $C$, Launay $D$, et al. Early detection of pulmonary arterial hypertension in systemic sclerosis: a French nationwide prospective multicenter study. Arthritis Rheum. 2005; 52(12):3792-800.

2. Wigley FM, Lima JAC, Mayes M, MCLain D, Chapin JL, Ward-Able C. The prevalence of undiagnosed pulmonary arterial hypertension in subjects with connective tissue disease at the secondary health care level of community-based rheumatologists (the UNCOVER study). Arthritis Rheum. 2005; 52(7):2125-32

3. Vonk MCBB, Heijdra YF, Ton E, Snijder R, van Dijk APJ, van Laar JM, Bootsma $H$, van Hal PTW, van den Hoogen FHJ, van Daele PLA. Systemic sclerosis and its pulmonary complications in The Netherlands: an epidemiological study. Ann Rheum Dis. 2009; 68(6):961-65.

4. Opie LH. The pulmonary manifestations of generalised scleroderma (progressive systemic sclerosis). Dis Chest. 1955; 28(6):665-80.

5. Humbert M, Yaici A, de Groote P, Montani D, Sitbon O, Launay D, Gressin V, Guillevin L, Clerson P, Simonneau G, Hachulla E. Screening for pulmonary arterial hypertension in patients with systemic sclerosis: clinical characteristics at diagnosis and long-term survival. Arthritis Rheum. 2011; 63(11):3522-30.

6. Steen VD, Medsger TA. Changes in causes of death in systemic sclerosis, 1972-2002. Ann Rheum Dis. 2007; 66(7):940-44.

7. Rodnan GP, Fennell RH Jr. Progressive systemic sclerosis sine scleroderma. JAMA. 1962; 180:665-70.

8. Blakemore WS, Forster RE, Morton JW, Ogilvie CM. A standardized breath holding technique for the clinical measurement of the diffusing capacity of the lung for carbon monoxide. J Clin Invest. 1957; 36(1 Part 1):1-17.

9. Carlsson M, Cain P, Holmqvist C, Stahlberg F, Lundback S, Arheden H. Total heart volume variation throughout the cardiac cycle in humans. Am J Physiol Heart Circ Physiol. 2004; 287(1):H243-250.

10. Ugander $\mathrm{M}$, Jense $\mathrm{E}$, Arheden H. Pulmonary intravascular blood volume changes through the cardiac cycle in healthy volunteers studied by cardiovascular magnetic resonance measurements of arterial and venous flow. J Cardiovasc Magn Reson. 2009; 11:42.

11. Ugander M, Kanski M, Engblom H, Gotberg M, Olivecrona GK, Erlinge D, Heiberg E, Arheden H. Pulmonary blood volume variation decreases after myocardial infarction in pigs: a quantitative and noninvasive MR imaging measure of heart failure. Radiology. 2010; 256(2):415-23.

12. Sackner MA. The visceral manifestations of scleroderma. Arthritis Rheum. 1962; 5:184-94.

13. Mukerjee D, Yap LB, Ong V, Denton CP, Howells K, Black CM, Coghlan JG. The myth of pulmonary Raynaud's phenomenon: the contribution of pulmonary arterial vasospasm in patients with systemic sclerosis related pulmonary arterial hypertension. Ann Rheum Dis. 2004; 63(12):1627-31.

14. LeRoy EC, Medsger TA Jr. Criteria for the classification of early systemic sclerosis. J Rheumatol. 2001; 28(7):1573-76.

15. Heiberg E, Sjogren J, Ugander M, Carlsson M, Engblom H, Arheden H. Design and validation of segment-freely available software for cardiovascular image analysis. BMC Med Imaging. 2010; 10:1. 
16. Pennell DJ. Ventricular volume and mass by CMR. J Cardiovasc Magn Reson. 2002; 4(4):507-13.

17. Mosteller RD. Simplified calculation of body-surface area. N Engl J Med. 1987; 317(17):1098.

18. Remy-Jardin M, Giraud F, Remy J, Copin MC, Gosselin B, Duhamel A. Importance of ground-glass attenuation in chronic diffuse infiltrative lung disease: pathologic-CT correlation. Radiology. 1993; 189(3):693-98

19. Yock PG, Popp RL. Noninvasive estimation of right ventricular systolic pressure by doppler ultrasound in patients with tricuspid regurgitation. Circulation. 1984; 70(4):657-62.

20. Donato L, Giuntini C, Lewis ML, Durand J, Rochester DF, Harvey RM, Cournand A. Quantitative radiocardiography. I. Theoretical considerations. Circulation. 1962; 26:174-82.

21. Giuntini C, Lewis ML, Luis AS, Harvey RM. A study of the pulmonary blood volume in man by quantitative radiocardiography. J Clin Invest. 1963; 42:1589-605.

22. McGaff CJ, Roveti GC, Glassman E, Milnor WR. Pulmonary blood volume in rheumatic heart disease and its alteration by isoproterenol. Circulation. 1963; 27:77-84.

23. Milnor WR, Jose AD, MCGaff CJ. Pulmonary vascular volume, resistance, and compliance in man. Circulation. 1960; 22:130-37.

24. Mischi M, Kalker TA, Korsten EH. Contrast echocardiography for pulmonary blood volume quantification. IEEE Trans Ultrason Ferroelectr Freq Control. 2004; 51(9):1137-47.

25. Ehler D, Carney DK, Dempsey AL, Rigling R, Kraft C, Witt SA, Kimball TR, Sisk EJ, Geiser EA, Gresser CD, et al. Guidelines for cardiac sonographer education: recommendations of the American society of echocardiography sonographer training and education committee. J Am Soc Echocardiogr. 2001; 14(1):77-84.

26. Her $C$, Hayes D, Lees DE. Elevated pulmonary artery systolic storage volume associated with redistribution of pulmonary perfusion. Crit Care Med. 1987; 15(11):1023-29.

27. Karatzas NB, Lee GJ. Propagation of blood flow pulse in the normal human pulmonary arterial system. Analysis of the pulsatile capillary flow. Circulation research. 1969; 25(1):11-21.

28. Roy SB, Bhardwaj P, Bhatia ML. Pulmonary blood volume in mitral stenosis. Br Med J. 1965; 2(5476):1466-69.

doi:10.1186/1532-429X-15-86

Cite this article as: Kanski et al:: Pulmonary blood volume indexed to lung volume is reduced in newly diagnosed systemic sclerosis compared to normals - a prospective clinical cardiovascular magnetic resonance study addressing pulmonary vascular changes. Journal of Cardiovascular Magnetic Resonance 2013 15:86.

\section{Submit your next manuscript to BioMed Central and take full advantage of:}

- Convenient online submission

- Thorough peer review

- No space constraints or color figure charges

- Immediate publication on acceptance

- Inclusion in PubMed, CAS, Scopus and Google Scholar

- Research which is freely available for redistribution
C Biomed Central 